\title{
Real-Time Interpretation Model of Reservoir Characteristics While Underbalanced Drilling Based on UKF
}

\author{
Miao He $\mathbb{D},{ }^{1,2}$ Yihang Zhang $\mathbb{D},{ }^{1}$ Mingbiao $\mathrm{Xu}^{1,2}$ Jun $\mathrm{Li}^{3}$ and Jianjian Song $\mathbb{D}^{1}$ \\ ${ }^{1}$ School of Petroleum Engineering, Yangtze University, Wuhan 430100, China \\ ${ }^{2}$ Hubei Cooperative Innovation Center of Unconventional Oil and Gas, Yangtze University, Wuhan 430100, China \\ ${ }^{3}$ China University of Petroleum Institute of Petroleum Engineering, Beijing 102249, China
}

Correspondence should be addressed to Miao He; hemiao@yangtzeu.edu.cn and Yihang Zhang; luckyzhangyh@foxmail.com

Received 22 October 2019; Revised 15 March 2020; Accepted 6 May 2020; Published 19 May 2020

Academic Editor: Shengnan Nancy Chen

Copyright ( 2020 Miao He et al. This is an open access article distributed under the Creative Commons Attribution License, which permits unrestricted use, distribution, and reproduction in any medium, provided the original work is properly cited.

This study presents a novel interpretation model for reservoir characteristics while underbalanced drilling (UBD), by incorporating an unscented Kalman filter (UKF) algorithm in a three-phase variable mass flow model of oil, gas, and liquid. In the model, the measurement parameters are simplified to bottomhole pressure and liquid outlet flow, for decreasing the amount of the computation and time. By taking into account real-time measurements, the permeability and reservoir pressure along the well can be continuously updated. Three cases including single-parameter and doubleparameter estimations have been simulated, and the performance is tested against the extended Kalman filter (EKF). The results show that single-parameter estimation of reservoir permeability or pressure achieves superior performance. The filtered values of bottomhole pressure and outlet flow trace the measured values in real time. When a new section of a reservoir is opened, the estimated reservoir permeability or pressure can always be quickly and accurately returned to its true value. However, it is not possible for the double-parameter estimation to obtain good results; its interpretation accuracy is low. UKF is superior to EKF in both estimation accuracy and convergence speed, which further illustrates the superiority and accuracy of the novel interpretation model based on UKF. Benefits from this model are seen in accurate bottomhole pressure and reservoir characteristic predictions, which are of major importance for safety and economic reasons during UBD and follow-up completion operations.

\section{Introduction}

Underbalanced drilling (UBD) is a technical means of drilling under the condition of negative pressure in a wellbore $[1,2]$. UBD began in the 1930s and developed rapidly in the recent years [3], because of its great advantages [4] in improving rate of penetration (ROP), discovering reservoirs, and reducing reservoir damage. When a reservoir is opened, formation fluid will enter the wellbore under the action of negative pressure difference, which will lead to changes in annulus pressure, flow rate, and other parameters $[5,6]$. Because of the coupling effect between the wellbore and formation, reservoir characteristics such as reservoir pressure and permeability may be obtained by using measured data acquired during drilling operation, such as bottomhole pressure, flow rate, and injection rate.
Estimation of the near wellbore characteristics of a reservoir gives important information in the drilling and completion process, helping the technical crew make better decisions. It is of great significance for early identifying a reservoir, reducing drilling risk, and improving drilling time. On this basis, Kardolus and Kruijsdijk [7] put forward the idea of formation characteristic interpretation while underbalanced drilling. Differently from the traditional approach, it needed not to go down the test string; the permeability profile near the wellbore was estimated while drilling based on a simplified analytical model. Actually, the joint hydraulics model and estimation algorithm is the basic theory of parameter interpretation. Several researches have addressed the basic theory works, respectively, for a two-phase flow modeling or estimation algorithm of UBD. Rommetveit et al. [8] presented a transient UBD simulator, DynaFloDrill, and the 
predictions were validated by the full-scale experiments performed with either parasite string or drill string gas injection. Lage et al. [9] proposed a composite discrete scheme for dynamic two-phase flow modelling, combining the firstorder Lax-Friedrichs and the second-order MacCormack format, to describe the transient behavior in UBD. Fjelde et al. [10] established a new multiphase flow model of UBD, which used the MUSCL format to modify the classical upwind format, and could better describe the pressure fluctuation law during pipe connection. Perez-Tellez et al. [11] proposed a mechanical model for predicting the pressure of two-phase flow in an annulus and a drill pipe, in which a drift flux model is coupled. Khezrian et al. [12] developed a two-fluid model in the Eulerian frame of reference for simulation of gas-liquid two-phase flow in the UBD operation. On this basis, Vefring et al. [13] evaluated the performance of the nonlinear least square methodology. The Levenberg-Marquardt optimization algorithm was used to estimate reservoir pressure and permeability in the UBD process. Tang [14] applied the damped least square method to study the interpretation of reservoir characteristics in underbalanced drilling. However, those approaches are both nonrecursive, which need to use all historical data, so they are best suited for postanalysis of data.

Kalman filter (KF) estimation methods have been widely used in oil industry in recent years, because of their better performance in real time. Vefring et al. [15] are the representative researchers in reservoir characteristic interpretation while underbalanced drilling. The measurements were set up as pump pressure, bottomhole pressure, and gas and liquid outlet flow. Based on the Levenberg-Marquardt and extended Kalman filter (EKF), interpretation models of reservoir pressure and permeability were established, in which EKF was a realtime recursive algorithm. Nazari et al. [16] introduced the unscented Kalman filter (UKF) to estimate the gas-liquid mixing velocity in the drill string and annulus. Several pressure sensors were installed in the annulus to improve the accuracy and robustness. Lorentzen et al. [17] designed an EKF method based on a two-phase flow model to regulate the key parameters of a drift flux model in UBD operation. Nikoofard et al. $[18,19]$ introduced a kind of nonlinear horizontal moving observer, which was used to estimate the liquid quality and liquid production coefficient of annular air in an underequilibrium state. Nygaard et al. [20] established a wellbore pressure control method based on the UKF algorithm to address the problem of pressure fluctuation caused by single connection and flow change when a gas reservoir was opened and conducted inversion interpretation for reservoir permeability. Gravdal et al. [21] established a pressure interpretation model by using the UKF algorithm, but only the friction coefficient was used as the estimated parameter.

Based on the previous researches, most of the Kalman filter studies on UBD use pump pressure, bottomhole pressure, and gas and liquid outlet flow parameters as the measurements. However, with more measurement parameters, the amount of the computation and time will be increased accordingly. The measurement parameters in the model need to be further optimized and evaluated due to their internal relations. Furthermore, currently there is still less research of using UKF in the UBD process.
In the present paper, a novel interpretation model for reservoir characteristics while underbalanced drilling is developed, by incorporating the UKF algorithm in a three-phase variable mass flow model of oil, gas, and liquid. The measurement parameters are simplified to bottomhole pressure and liquid outlet flow, to continuously update the permeability and reservoir pressure along the well. Based on this interpretation, the future state of the reservoir system near the wellbore can be predicted, helping the management of the wellbore during UBD and follow-up completion operations.

The outline of the paper is as follows. First, the threephase variable mass flow model of oil, gas, and liquid, including a drift flux model and frictional pressure loss model, is presented. Then, the real-time estimation method of UKF is described. Finally, results from simulations performed with three cases, like reservoir permeability and pressure singleparameter estimation and double-parameter estimation, are conducted. The performance of UKF is also evaluated against EKF in permeability single-parameter estimation.

\section{Three-Phase Variable Mass Flow Model of Oil, Gas, and Liquid}

Underbalanced drilling technology is realized by gas injection into a drill string. When underbalanced drilling encounters reservoirs, the oil and gas in the formation will continue to flow into the wellbore. With the elapse of time, reservoir gas and oil rise upward in the wellbore and reservoir opening length prolongs, resulting in a gradual increase in reservoir production. Therefore, the wellbore is actually a variable mass flow system consisting of injected gas, drilling fluid, produced gas, produced oil, and cutting multiphase components.

A mathematical model of three-phase variable mass flow of oil, gas, and liquid is established based on the theory of a wellbore multiphase flow and dynamic reservoir model $[22,23]$. The basic assumptions are as follows:

(1) The wellbore fluid flows in one dimension, ignoring the radial flow change

(2) Drilling fluid is water-based mud (WBM), set as the Herschel-Bulkley model, without considering the mass transfer between oil, gas, and liquid phases

(3) Ignoring the influence of heat transfer between the wellbore and formation, one can calculate the temperature in the wellbore by a linear geothermal gradient

(4) The effect of cuttings on wellbore flow is small, so it is not considered

2.1. Multiphase Flow Equation. The mass conservation equation of injected gas is

$$
\frac{\partial}{\partial t}\left(x_{\mathrm{ig}} \rho_{\mathrm{g}} \alpha_{\mathrm{g}} A\right)+\frac{\partial}{\partial z}\left(x_{\mathrm{ig}} \rho_{\mathrm{g}} \alpha_{\mathrm{g}} v_{\mathrm{g}} A\right)=0
$$


The mass conservation equation of drilling fluid is

$$
\frac{\partial}{\partial t}\left(\rho_{1} \alpha_{1} A\right)+\frac{\partial}{\partial z}\left(\rho_{1} \alpha_{1} v_{1} A\right)=0
$$

The mass conservation equation of produced gas is

$$
\frac{\partial}{\partial t}\left(x_{\mathrm{fg}} \rho_{\mathrm{g}} \alpha_{\mathrm{g}} A\right)+\frac{\partial}{\partial z}\left(x_{\mathrm{fg}} \rho_{\mathrm{g}} \alpha_{\mathrm{g}} v_{\mathrm{g}} A\right)=q_{\mathrm{fg}} .
$$

The mass conservation equation of produced oil is

$$
\frac{\partial}{\partial t}\left(\rho_{\mathrm{o}} \alpha_{\mathrm{o}} A\right)+\frac{\partial}{\partial z}\left(\rho_{\mathrm{o}} \alpha_{\mathrm{o}} v_{\mathrm{o}} A\right)=q_{\mathrm{o}} .
$$

The three-phase momentum conservation equation of oil, gas, and water is

$$
\begin{aligned}
& \frac{\partial}{\partial t}\left(\rho_{\mathrm{g}} \alpha_{\mathrm{g}} v_{\mathrm{g}} A+\rho_{\mathrm{l}} \alpha_{\mathrm{l}} v_{\mathrm{l}} A+\rho_{\mathrm{o}} \alpha_{\mathrm{o}} v_{\mathrm{o}} A\right) \\
& \quad+\frac{\partial}{\partial z}\left(\rho_{\mathrm{g}} \alpha_{\mathrm{g}} v_{\mathrm{g}}^{2} A+\rho_{\mathrm{l}} \alpha_{\mathrm{l}} v_{\mathrm{l}}^{2} A+\rho_{\mathrm{o}} \alpha_{\mathrm{o}} v_{\mathrm{o}}^{2} A\right) \\
& \quad+\left(\rho_{\mathrm{g}} \alpha_{\mathrm{g}}+\rho_{\mathrm{l}} \alpha_{\mathrm{l}}+\rho_{\mathrm{o}} \alpha_{\mathrm{o}}\right) g \sin \theta A+\frac{\partial(p A)}{\partial z}+A \frac{\partial p_{\mathrm{f}}}{\partial z}=0
\end{aligned}
$$

The $P-V-T$ equation is

$$
\rho_{\mathrm{g}}=\frac{M_{\mathrm{g}} p}{Z R T}
$$

The gas-liquid drift flux model is calculated as

$$
v_{\mathrm{g}}=c_{0} v_{\mathrm{m}}+v_{\mathrm{gr}}
$$

The model of frictional pressure loss along the well is calculated as

$$
\frac{\partial p_{\mathrm{f}}}{\partial z}=\frac{2 f \rho_{\mathrm{m}} v_{\mathrm{m}}}{D}\left|v_{\mathrm{m}}\right|+\frac{\partial p_{\mathrm{ac}}}{\partial z}
$$

where $A$ is the annular area. $\rho_{\mathrm{g}}, \rho_{\mathrm{l}}$, and $\rho_{\mathrm{o}}$ are the density of gas, drilling fluid, and oil, respectively. $\alpha_{\mathrm{g}}, \alpha_{1}$, and $\alpha_{\mathrm{o}}$ are the volume fraction of gas, drilling fluid, and oil, respectively. $v_{\mathrm{g}}, v_{\mathrm{l}}$, and $v_{\mathrm{o}}$ are the actual flow rates of gas, drilling fluid, and oil, respectively. $x_{\mathrm{ig}}$ and $x_{\mathrm{fg}}$ are the mass fraction of injected gas and produced gas, respectively. $q_{\mathrm{fg}}$ and $q_{\mathrm{o}}$ are the influx rate of gas and oil phases. $g$ is the gravitational acceleration. $\theta$ is the angle between the wellbore and horizontal direction. $p_{\mathrm{f}}$ is the pressure drop. $p_{\mathrm{ac}}$ is the acceleration pressure drop. $M_{\mathrm{g}}$ is the molar mass of the gas. $p$ is the wellbore pressure. $Z$ is the deviation factor, solved by the PR-EOS model [24]. $R$ is a general gas constant. $c_{0}$ is the gas phase distribution coefficient. $v_{\text {gr }}$ is the gas slip velocity. $f$ is the fanning friction coefficient. $\rho_{\mathrm{m}}$ is the density of gas-liquid mixture. $v_{\mathrm{m}}$ is the velocity of gas-liquid mixture. $D$ is the equivalent diameter.

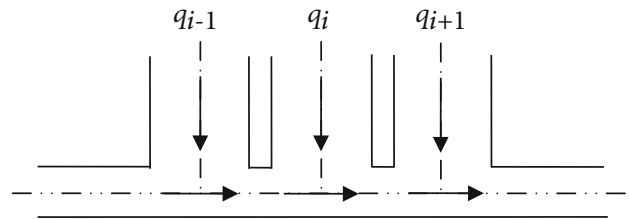

FIGURE 1: Diagram of wellbore-reservoir coupling variable mass flow.

Distribution coefficients, slip velocity parameters, and pressure drop model will change with the change of a gasliquid two-phase flow pattern. Therefore, accurate flow pattern identification is an important prerequisite for establishing a comprehensive multiphase flow mathematical model. The flow pattern transition of gas-liquid two-phase flow is a complex physical process. With the change of volume fraction, velocity, pressure, and relative position of the twophase medium, the shape of the interface changes, which leads to the change of the flow pattern. At present, there is no mature theoretical support for the physical mechanism of flow pattern transition. For different flow pattern changes, empirical formulas of relevant parameters are often fitted by means of experiments, and then, critical conditions of flow pattern transition are determined. According to previous research results [25-27], two-phase flow patterns in the vertical wellbore are divided into five categories: bubble flow, dispersed bubble flow, slug flow, churn flow, and annular flow. For different flow patterns, the distribution coefficients, slip velocity, and pressure drop along the well are determined. The multiphase flow model is solved by a simple front tracking technique and finite difference numerical method. The specific algorithm and formula are not described here. A previous paper by $\mathrm{He}$ et al. [28] has introduced the algorithms and formulas in detail.

2.2. Dynamic Reservoir Model. When reservoir oil and gas influx occurs in the drilling process, the influx mode is negative pressure influx, which can be regarded as plane radial flow in isotropic homogeneous elastic porous media. The Dake model [29] with an analytic solution is used to describe the flow process. In the process of underbalanced drilling, the opened zones of the reservoir are all involved in the coupled flow with the wellbore, thus forming the whole variable mass flow process. The opened reservoir is divided into $n$ units along the axis of the wellbore, as shown in Figure 1. The dynamic reservoir model can be expressed as follows:

$$
q_{i}\left(t_{i}\right)=\frac{4 \pi k_{i} \Delta h\left(p_{\mathrm{r}, i}-p_{\mathrm{a}, i}\right)}{\mu\left[2 S+\ln \left(4 k_{i} t_{i} / e^{\gamma} \phi \mu c r_{\mathrm{w}}{ }^{2}\right)\right]},
$$

where $p_{\mathrm{a}}$ is the annular pressure. $p_{\mathrm{r}}$ is the reservoir pressure. $q$ is the influx rate. $k$ is the reservoir permeability. $S$ is the skin factor. $\Delta h$ is the length of the open reservoir interval per unit time. $t$ is the duration of the open reservoir interval. $\varphi$ is the reservoir porosity. $\mu$ is the viscosity of reservoir fluid. $c$ is the compressibility coefficient of reservoir fluid. $r_{\mathrm{w}}$ is the borehole radius. $\gamma$ is the Euler constant. 


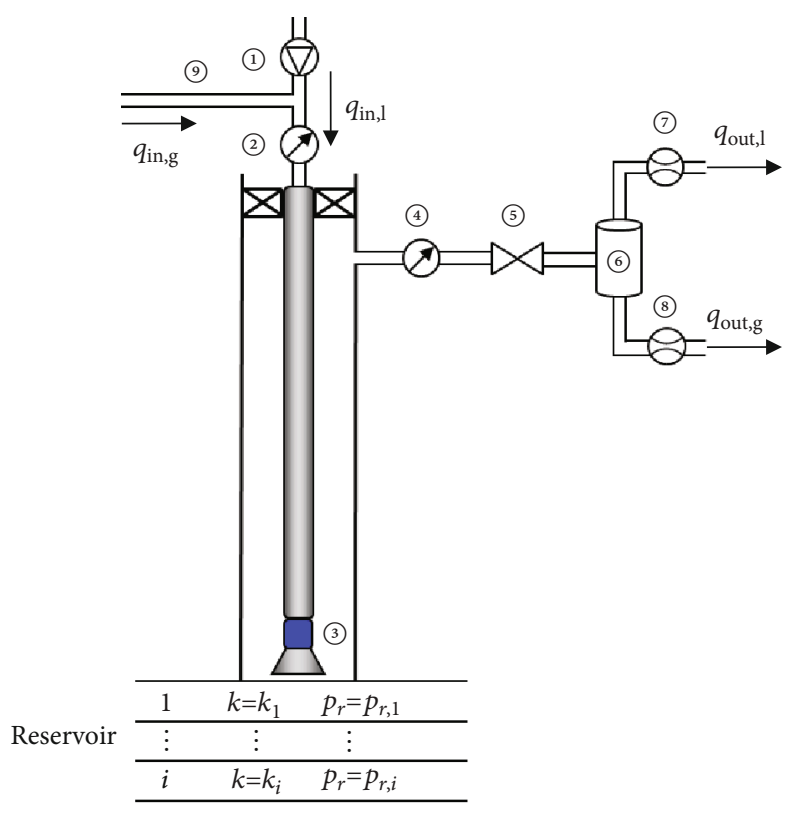

(1) Mud pump

(2) Standpipe pressure gauge

(3) PWD

(4) Casing pressure gauge

(5) Choke valve

FIGURE 2: Diagram of underbalanced drilling of gas injection in the drill string.

\section{Interpretation Model of Reservoir Characteristics Based on UKF}

3.1. Determination of Interpretation Model Parameters. The description of the gas injection in the drill string of underbalanced drilling technology is as follows: gas passes through the gas injection pipeline, mixes with the drilling fluid pumped by a mud pump, and jointly injects into the drill string. With the opening of the reservoir section during drilling, reservoir oil and gas fluids gradually influx into the wellbore and return to the wellhead together with the injected gas and drilling fluids. After passing through the gas-liquid separator on the ground, the gas phase and liquid phase are finally separated. The schematic diagram is shown in Figure 2.

In the previous literature, pump pressure, bottomhole pressure, and gas and liquid outlet flow rate were often regulated as measurement parameters. The bottomhole pressure is measured by pressure while drilling (PWD) instruments. However, according to the principle of the U-tube, the pressure transfer relation can be constructed in the drill string between bottomhole pressure and pump pressure. In addition, there is a mathematical relationship between the gasliquid outlet flow rate and wellbore-reservoir coupled flow system. Because the mass transfer of gas and liquid is not considered, according to the superposition principle, the sum of gas-liquid outlet flow is equal to the sum of inlet flow, reservoir influx rate, and gas expansion rate. The formulas are as follows:

$$
\begin{gathered}
p_{\mathrm{b}}=p_{\mathrm{s}}+p_{\mathrm{h}}-\Delta p_{\mathrm{d}}-\Delta p_{\mathrm{t}} \\
q_{\text {out }, \mathrm{l}}+q_{\text {out }, \mathrm{g}}=q_{\mathrm{in}, \mathrm{l}}+q_{\mathrm{in}, \mathrm{g}}+q_{\mathrm{inf}}+q_{\mathrm{exp}} .
\end{gathered}
$$

Therefore, the measurement parameters can be simplified into two categories: bottomhole pressure and liquid outlet flow. The expressions are as follows:

$$
\begin{aligned}
p_{\mathrm{b}} & =\left[p_{\mathrm{b}}\left(t_{1}\right), p_{\mathrm{b}}\left(t_{2}\right), \cdots, p_{\mathrm{b}}\left(t_{N}\right)\right], \\
q_{\text {out }, \mathrm{l}} & =\left[q_{\text {out }, \mathrm{l}}\left(t_{1}\right), q_{\text {out }, \mathrm{l}}\left(t_{2}\right), \cdots, q_{\text {out }, \mathrm{l}}\left(t_{N}\right)\right],
\end{aligned}
$$

where $p_{\mathrm{b}}$ is the bottomhole pressure. $p_{\mathrm{s}}$ is the pump pressure. $p_{\mathrm{h}}$ is the hydrostatic column pressure in the drill string. $\Delta p_{\mathrm{d}}$ is the circulating pressure loss in the drill string. $\Delta p_{\mathrm{t}}$ is the pressure loss of the drill bit. $q_{\text {out,l }}$ and $q_{\text {out,g }}$ represent liquid and gas outlet flow rates, respectively. $q_{\mathrm{in}, \mathrm{l}}$ and $q_{\mathrm{in}, \mathrm{g}}$ indicate liquid and gas inlet flow, respectively. $q_{\text {inf }}$ is the reservoir influx flow rate. $q_{\exp }$ is the gas expansion rate. $t_{1}, t_{2}, \cdots, t_{N}$ is the $N$ points of time corresponding to the measured data.

Generally, reservoir lithology is complex, and the internal pore and fracture distribution is random and nonuniform. Therefore, the reservoir to be drilled can be subdivided into several units. Reservoir permeability $k$ and reservoir pressure $p_{r}$ of each unit may be different, as shown in Figure 2. Reservoir permeability and pressure are determined as interpretation parameters of the model, and the expressions are as follows:

$$
\begin{aligned}
k & =\left[k\left(t_{1}\right), k\left(t_{2}\right), \cdots, k\left(t_{N}\right)\right], \\
p_{\mathrm{r}} & =\left[p_{\mathrm{r}}\left(t_{1}\right), p_{\mathrm{r}}\left(t_{2}\right), \cdots, p_{\mathrm{r}}\left(t_{N}\right)\right] .
\end{aligned}
$$

3.2. UKF Algorithm. The initial Kalman filtering technique is only suitable for linear systems [30], but most of the real problems are essentially nonlinear. Then, an extended Kalman filter and unscented Kalman filter are developed successively for nonlinear systems [31-33]. The main difference between EKF and UKF is the way Gaussian random variables are represented for propagating through system dynamics. UKF adopts a deterministic sampling method with a minimal set of carefully chosen sample points, instead of the local linearization in EKF. These sample points are propagated through the nonlinear system and capture the posterior mean and covariance accurately to the third order for all nonlinearities. In contrast to EKF, UKF appears later and requires no calculation of the complex Jacobian matrix and is a more advanced nonlinear filtering technology.

Using UKF, it is possible to combine the information obtained from the measurements with the model to get an improved real-time estimate of the state vector of the system. The state vector is the interpretation parameter. Combined with the discussion in Section 3.1, the state vector $x$ and the measurement $z$ in the model are determined as follows, 
where the subscript $k$ denotes the time $k$.

$$
\begin{aligned}
& x=\left[k\left(t_{k}\right), p_{\mathrm{r}}\left(t_{k}\right)\right]^{T}, \\
& z=\left[p_{\mathrm{b}}\left(t_{k}\right), p_{\text {out }, \mathrm{l}}\left(t_{k}\right)\right]^{T} .
\end{aligned}
$$

The state space form of the nonlinear system based on state estimation is as follows:

$$
\begin{aligned}
& x_{k}=f\left(x_{k-1}\right)+w_{k-1}, \\
& z_{k}=h\left(x_{k}\right)+v_{k},
\end{aligned}
$$

where $x_{k}$ is a state vector. $\mathrm{f}(\cdot)$ is a nonlinear system state function. $z_{k}$ is a measurement vector. $\mathrm{h}(\cdot)$ is a nonlinear measurement function, which represents the variable mass flow model in this work. $w_{k}$ and $v_{k}$ are, respectively, the process noise and measurement noise of the system, which satisfy the zero mean white noise distribution, $\mathrm{w}_{k} \sim N\left\{0, Q_{k}\right\}$, and $\mathrm{v}_{k} \sim N\left\{0, R_{k}\right\}$, and they are not related to each other.

The structure of UKF is basically the same as that of EKF, which is mainly divided into two processes: state update and measurement update. The process of state update means that the estimated value at the previous time is known, the current state variables and the estimated error covariance matrix are predicted by using the state model, and a prior estimate is constructed for the next time state. The measurement update process is responsible for feedback, and the posterior estimate of the current state is corrected by combining the prior estimate with a new measurement data. Therefore, this algorithm can also be called a predictor-corrector algorithm.

Firstly, the prior estimation mean of the state vector at the initial time is set to $\widehat{\mathrm{x}}_{0}$, and the estimation error covariance matrix $P_{0}$ is set.

According to the state vector of timestep $k-1$, the estimation of timestep $k$ can be obtained.

$$
\left\{\begin{array}{l}
\hat{x}_{k}=\widehat{x}_{k-1}, \\
P_{k}=P_{k-1}+Q_{k-1} .
\end{array}\right.
$$

$2 L+1$ sigma points $\mathrm{x}_{\mathrm{i}}$ are constructed, where $L$ is the dimension of the state vector, and the set of sigma points can be expressed as

$$
\widehat{x}_{i, k-1}= \begin{cases}\widehat{x}_{k-1}, & i=0, \\ \widehat{x}_{k-1}+\left(\sqrt{(L+\lambda) P_{k-1}}\right)_{i}, & i=1, \cdots, L, \\ \widehat{x}_{k-1}-\left(\sqrt{(L+\lambda) P_{k-1}}\right)_{i}, & i=n+1, \cdots, 2 L,\end{cases}
$$

where $\left(\sqrt{(L+\lambda) P_{k-1}}\right)$ is the $i$ th column of the matrix square root, which is calculated by the Cholesky decomposition. $\alpha$ represents the spread of the sigma points around the current state vector and is usually set as a small positive value, ranging from $[0,1] \cdot \lambda=\alpha^{2}(L+\kappa)-L$ is a scaling parameter. $\kappa$ is a secondary scaling parameter. If $L \leq 3, \kappa=3$-L; if $L>3, \kappa=0$.
For each sigma point, the transformed result is obtained by nonlinear transformation $\mathrm{f}(\cdot)$.

$$
x_{i, k / k-1}=f\left(x_{i, k-1}\right), \quad i=0,1, \cdots, 2 L .
$$

$\mathrm{x}_{\mathrm{i}, \mathrm{k} / \mathrm{k}-1}$ is weighted to predict the prior estimates of mean $\widehat{\mathrm{x}}_{\mathrm{k} / \mathrm{k}-1}$ and covariance matrix $\mathrm{P}_{\mathrm{k} / \mathrm{k}-1}$.

$$
\begin{aligned}
& \widehat{x}_{k / k-1}=\sum_{i=0}^{2 L} W_{i}^{(\mathrm{m})} x_{i, k / k-1}, \\
& P_{k / k-1}=\sum_{i=0}^{2 L} W_{i}^{(\mathrm{c})}\left[x_{i, k / k-1}-\widehat{x}_{k / k-1}\right]\left[x_{i, k / k-1}-x \wedge_{k / k-1}\right]^{T}+Q_{k-1} \text {, } \\
& W_{i}^{(\mathrm{m})}= \begin{cases}\frac{\lambda}{L+\lambda}, & i=0, \\
\frac{1}{2(L+\lambda)}, & i \neq 0,\end{cases}
\end{aligned}
$$

$W_{i}^{(\mathrm{c})}= \begin{cases}\frac{\lambda}{L+\lambda}+1+\beta-\alpha^{2}, & i=0, \\ \frac{1}{2(L+\lambda)}, & i \neq 0,\end{cases}$

where $W_{\mathrm{i}}^{(\mathrm{m})}$ and $W_{i}^{(\mathrm{c})}$ are weighted by mean and covariance, respectively. $\beta$ is a scaling parameter, used to include the information about the distribution. For the Gaussian distribution, $\beta=2$ is optimal.

Similarly, the nonlinear measurement function $\mathrm{h}(\cdot)$ is used to transfer the sigma point to $\mathrm{z}_{\mathrm{i}, \mathrm{k} / \mathrm{k}-1}$ and to predict the measurement value $\widehat{z}_{k / k-1}$, the autocovariance matrix $P_{z_{k}}$, and the crosscovariance matrix $\mathrm{P}_{\mathrm{x}_{\mathrm{k}} \mathrm{z}_{\mathrm{k}}}$.

$$
\begin{aligned}
z_{i, k / k-1} & =h\left(x_{i, k-1}\right), \quad i=0,1, \cdots, 2 L, \\
\widehat{z}_{k / k-1} & =\sum_{i=0}^{2 L} W_{i}^{(\mathrm{m})} z_{i, k / k-1}, \\
P_{z_{k}} & =\sum_{i=0}^{2 L} W_{i}^{(\mathrm{c})}\left[z_{i, k / k-1}-\widehat{z}_{k / k-1}\right]\left[z_{i, k / k-1}-z \wedge_{k / k-1}\right]^{T}+R_{k}, \\
P_{x_{k} z_{k}} & =\sum_{i=0}^{2 L} W_{i}^{(\mathrm{c})}\left[x_{i, k / k-1}-\widehat{x}_{k / k-1}\right]\left[z_{i, k / k-1}-z \wedge_{k / k-1}\right]^{T} .
\end{aligned}
$$

Finally, calculate the gain matrix $\mathrm{K}_{\mathrm{k}}$, and update the state mean $\widehat{\mathrm{x}}_{\mathrm{k}}$ and covariance matrix $\mathrm{P}_{\mathrm{k}}$ at timestep $k$ based on a new measured value $\mathrm{z}_{\mathrm{k}}$.

$$
\begin{aligned}
K_{k} & =P_{x_{k} z_{k}} P_{z_{k}}^{-1}, \\
\widehat{x}_{k} & =\widehat{x}_{k / k-1}+K_{k}\left(z_{k}-\widehat{z}_{k / k-1}\right), \\
P_{k} & =P_{k / k-1}-K_{k} P_{z_{k}} K_{k}^{T} .
\end{aligned}
$$


TABLE 1: Basic parameters for well X.

\begin{tabular}{|c|c|c|c|}
\hline Parameters & Value & Parameters & Value \\
\hline Well depth (m) & 3000 & Yield point $(\mathrm{Pa})$ & 3.84 \\
\hline Casing shoe depth (m) & 2200 & Surface temperature $\left({ }^{\circ} \mathrm{C}\right)$ & 20 \\
\hline Casing ID (mm) & 228.47 & Geothermal gradient $\left({ }^{\circ} \mathrm{C} / \mathrm{m}\right)$ & 0.0266 \\
\hline Bit diameter $(\mathrm{mm})$ & 215.9 & Casing pressure $(\mathrm{MPa})$ & 1 \\
\hline Drill pipe OD (mm) & 127 & Gas injection rate $\left(\mathrm{Nm}^{3} / \mathrm{s}\right)$ & 0.5 \\
\hline Drill pipe ID (mm) & 108.6 & $\operatorname{ROP}(\mathrm{m} / \mathrm{h})$ & 16 \\
\hline Bit nozzle area $\left(\mathrm{mm}^{2}\right)$ & 660 & Oil density $\left(\mathrm{kg} / \mathrm{m}^{3}\right)$ & 850 \\
\hline Pump rate $(\mathrm{L} / \mathrm{s})$ & 30 & Oil viscosity $(\mathrm{mPa} \cdot \mathrm{s})$ & 30 \\
\hline Mud density $\left(\mathrm{kg} / \mathrm{m}^{3}\right)$ & 1180 & Compressibility of liquid $\left(\mathrm{Pa}^{-1}\right)$ & $1.0 \times 10^{-9}$ \\
\hline Consistency index $\left(\mathrm{Pa} \cdot \mathrm{s}^{n}\right)$ & 0.37 & Reservoir porosity & 0.15 \\
\hline Flow behavior index & 0.68 & Skin factor & 0.013 \\
\hline
\end{tabular}

\section{Numerical Simulation Analysis}

Based on the interpretation model while underbalanced drilling established above, real-time estimation of reservoir characteristics is carried out. Because the interpretation parameters of the model are reservoir pressure and permeability, they are difficult to be obtained under the current laboratory and field test conditions. Thus, this paper uses the synthetic data instead of the experimental data as measurements. Calculation steps are as follows: Firstly, a set of reservoir characteristic parameters (pressure and permeability) are preset as the estimates of interpretation parameters of the open reservoir section at the initial time. Then, the bottomhole pressure and outlet flow are simulated by using the established hydraulics model as measurements. Finally, the interpretation parameters are online estimated by using the UKF algorithm.

Well $\mathrm{X}$ is drilled in underbalanced condition by gas injection in the drill string. The injected gas phase is nitrogen. The reservoir is drilled at $3000 \mathrm{~m}$, which is a pure oil reservoir. The reservoir is a typical medium-permeability sandstone reservoir with permeability ranging from $50 \mathrm{mD}$ to $500 \mathrm{mD}$. Shale is the upper caprock, and low-permeability mudstone is the interlayer. Vertical distribution of sand and mud is interactive. The basic data needed for the well calculation are shown in Table 1.

The drilling process of the 3000-3100 m reservoir section is simulated. By dividing the reservoir into five units, each unit is $20 \mathrm{~m}$ in length. The reservoir pressure and permeability of each unit are constant. In order to analyze the influence of interpretation parameter dimension on the results of model estimation, we have carried out three cases, each of which has different interpretation parameters. Case 1 and case 2 are single-parameter estimates. The single parameter of reservoir permeability or formation pressure is estimated as the interpretation parameter, respectively. Case 3 is a double-parameter estimate, and the reservoir permeability and pressure are both estimated as interpretation parameters. The true value of reservoir permeability and pressure of five units is given in each case: case 1: reservoir permeability is $[250,500,350,150,50] \mathrm{mD}$ and reservoir pressure has a fixed value $(38 \mathrm{MPa})$; case 2 : reservoir pressure is $[38,44,40,36$,
42] $\mathrm{MPa}$ and reservoir permeability has a fixed value $(400 \mathrm{mD})$; and case 3 : reservoir permeability is $[250,500$, $350,150,50] \mathrm{mD}$ and reservoir pressure is $[38,44,40,36$, 42] $\mathrm{MPa}$.

Note that the proper specification of the covariance matrix for the modeling error is crucial to get better performance of the filter. The covariance matrix for state parameter error $Q$ and measurement error $R$ are almost diagonal, which depends on the specific case of the research object, while the uncertainty parameters may be related to each other. Although the relationship between those parameters and the effect on the interpretation performance are not the focus of this paper, they can be a topic for further research. We assume that the errors in the measurements and state parameter are statistically independent and are set as a suitable value with personal experience. The standard deviations of reservoir pressure and permeability process noise are $0.15 \mathrm{MPa}$ and $0.5 \mathrm{mD}$, respectively, while the accuracy of bottomhole pressure and outlet flow measurement is $0.05 \%$ and $0.1 \%$, respectively; i.e., the standard deviations of measurement noise are $0.02 \mathrm{MPa}$ and $0.00003 \mathrm{~m}^{3} / \mathrm{s}$, respectively. Thus, the covariance matrix for parameter and measurement error in three cases is as follows:

Case 1. $Q=\operatorname{diag}\left[0.5^{2}\right], R=\operatorname{diag}\left[0.02^{2}, 0.00003^{2}\right]$

Case 2. $Q=\operatorname{diag}\left[0.15^{2}\right], R=\operatorname{diag}\left[0.02^{2}, 0.00003^{2}\right]$

Case 3. $Q=\operatorname{diag}\left[0.5^{2}, 0.15^{2}\right], R=\operatorname{diag}\left[0.02^{2}, 0.00003^{2}\right]$

Cases 1, 2, and 3 show that gas is injected from the drill string and then returned from the annulus wellhead, reaching to a steady state $(0-75 \mathrm{~min})$. The gas injection process is the common part of three cases, which are described in detail here. $0-15.5 \mathrm{~min}$ is the process of injected gas from the drill string to the drill bit. At this stage, the bottomhole pressure increases slightly and basically keeps unchanged, and the outlet flow increases with the gas injection at the initial time, then gradually decreases. $15.5-51.1 \mathrm{~min}$ is the process of gas migration from the bottomhole to the wellhead annulus. In this stage, the bottomhole pressure continues to decrease, 


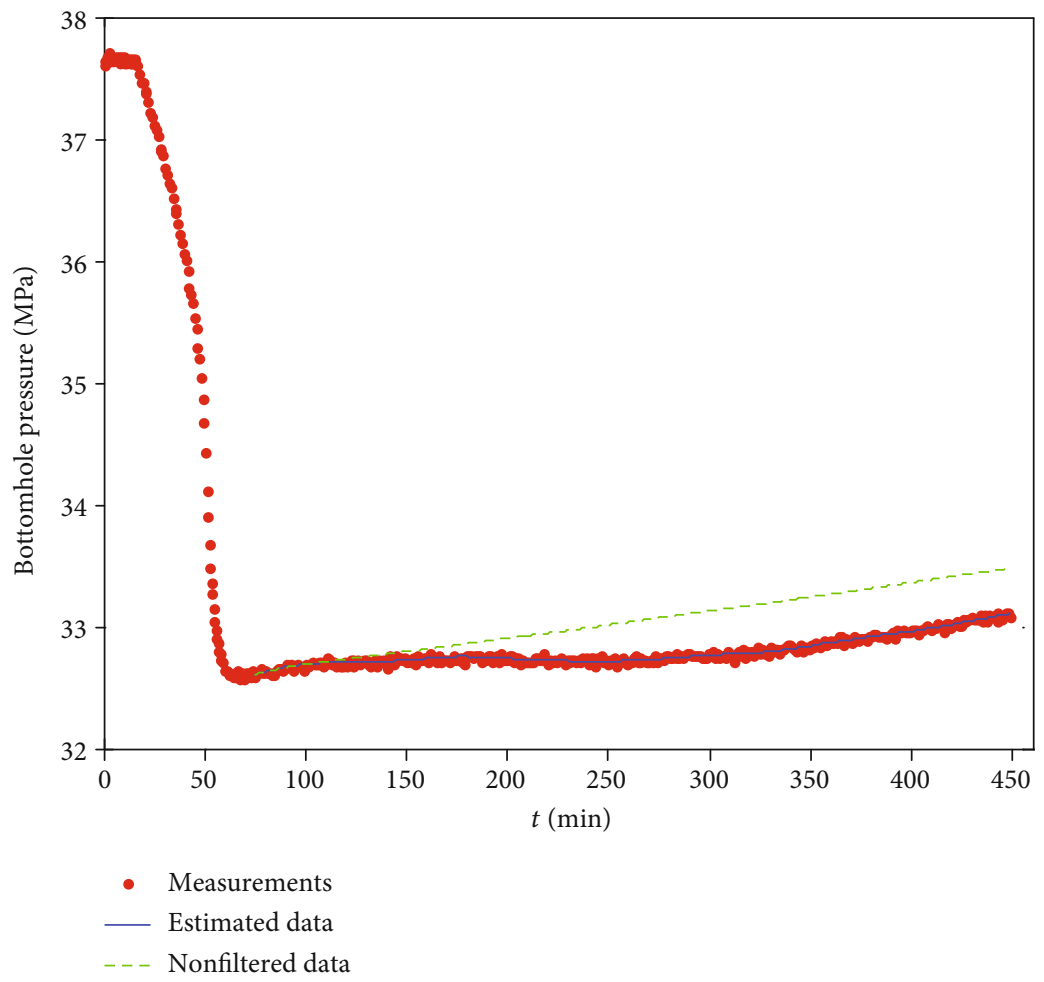

FIgURE 3: Bottomhole pressure variation (case 1).

while the outlet flow gradually increases due to the gas migration. 51.1-75 $\mathrm{min}$ is the process of gas front reaching wellhead annulus to wellbore stable-state flow. Bottomhole pressure continues to decrease at first, then tends to be constant, and the outlet flow quickly falls back to the inlet pump rate of $0.03 \mathrm{~m}^{3} / \mathrm{s}$.

For case 1, the reservoir pressure is known to be $38 \mathrm{MPa}$ and the reservoir permeability is estimated. The calculation results are shown in Figures 3-5. Figures 3 and 4 show the comparison between the estimated data and measurements of bottomhole pressure and outlet flow rate, respectively. It can be seen that $75 \mathrm{~min}$ is the initial point of drilling in the reservoir section and real-time interpretation starts synchronously at this time. 450 minutes is the end point, when the reservoir is just opened $100 \mathrm{~m}$ in length. The estimated value of bottomhole pressure and outlet flow basically coincides with the measured value. Because of the influence of measurement noise, the measured value is somewhat burr, while the filtered curve (i.e., the blue line) is smoother. However, the calculated values of bottomhole pressure and outlet flow rate without filter processing (i.e., the green line) deviate from the measurements. The setting condition of the nonfilter is that the reservoir permeability is a constant value.

Figure 5 shows the comparison between the true and estimated permeability values. The simulation results show that the true values of permeability of each reservoir unit are [250, $500,350,150,50] \mathrm{mD}$ and the initial value is set to $100 \mathrm{mD}$. $75-150 \mathrm{~min}$ is the time period of opening reservoir unit 1 . With the elapse of time, the estimated value of reservoir permeability gradually rises from $100 \mathrm{mD}$ to its true value near $150 \mathrm{mD}$ and then basically fluctuates slightly around the true value. When unit 2 is opened (150-225 $\mathrm{min})$, the reservoir permeability gradually approaches its true value of $500 \mathrm{mD}$ from $150 \mathrm{mD}$, and then, analogies are made until the whole $100 \mathrm{~m}$ reservoir section is opened. Therefore, the estimated value of reservoir permeability is in good agreement with the true value. When a new section of the reservoir is opened, the estimated value can always be accurately and quickly returned to its true value.

For case 2, the reservoir permeability is preset as $400 \mathrm{mD}$ and the reservoir pressure is estimated. The calculation results are shown in Figures 6-8. Figures 6 and 7 show the comparison between the estimated data and measurements of bottomhole pressure and outlet flow rate, respectively. The estimated values of bottomhole pressure and outlet flow are basically in agreement with the measurements, while the nonfiltered data deviate greatly from the measurements. Figure 8 shows the comparison between the true and estimated reservoir pressure values. It can be seen that the true values of reservoir pressure in each unit are $[38,44,40,36$, 42] $\mathrm{MPa}$ and the initial value is set to $34 \mathrm{MPa}$. The estimation of reservoir pressure is in good agreement with the real value. When a new section of the reservoir is opened, the estimation of reservoir pressure can quickly approach its true value. Compared with example 1, it takes shorter time and converges faster.

The double parameters of reservoir permeability and pressure are estimated simultaneously in case 3 . The simulation results are shown in Figures 9-12. Figures 9 and 10, respectively, show the comparison between the estimated data and measurements of bottomhole pressure and outlet flow. Similarly, the estimated values of bottomhole pressure 


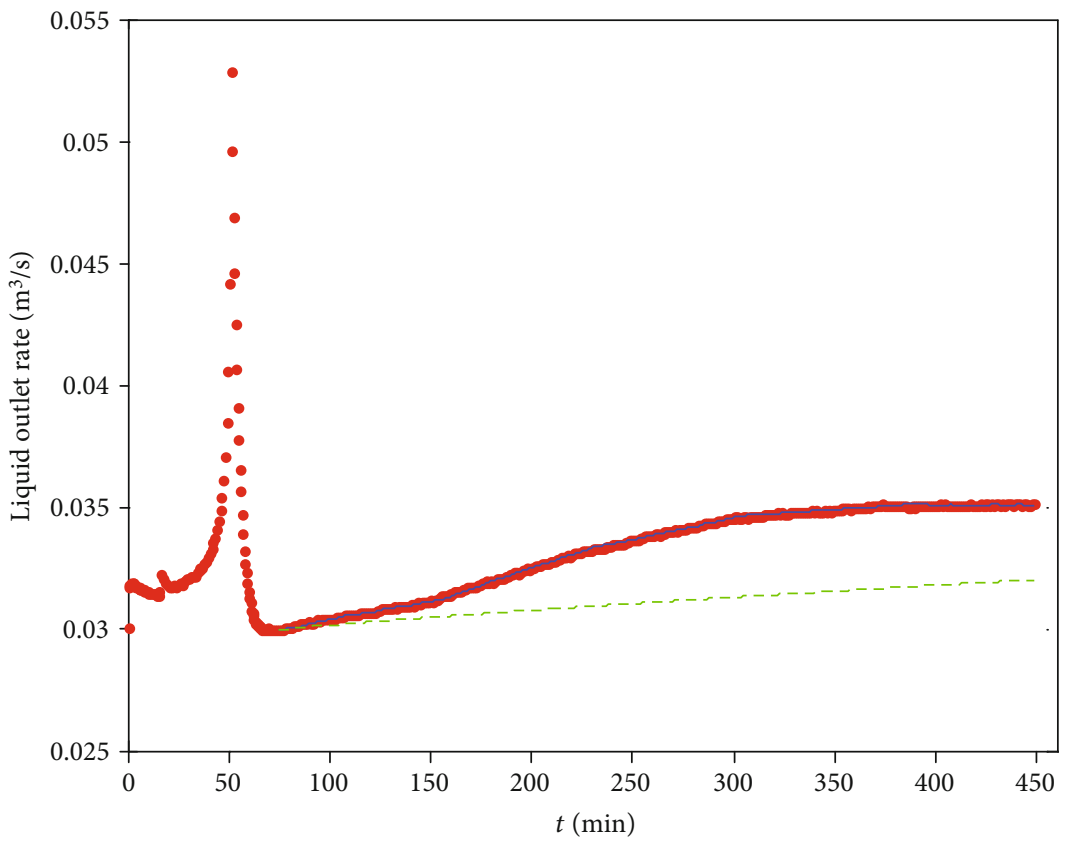

- Measurements

Estimated data

- . - Nonfiltered data

FIgURE 4: Liquid outlet rate variation (case 1).

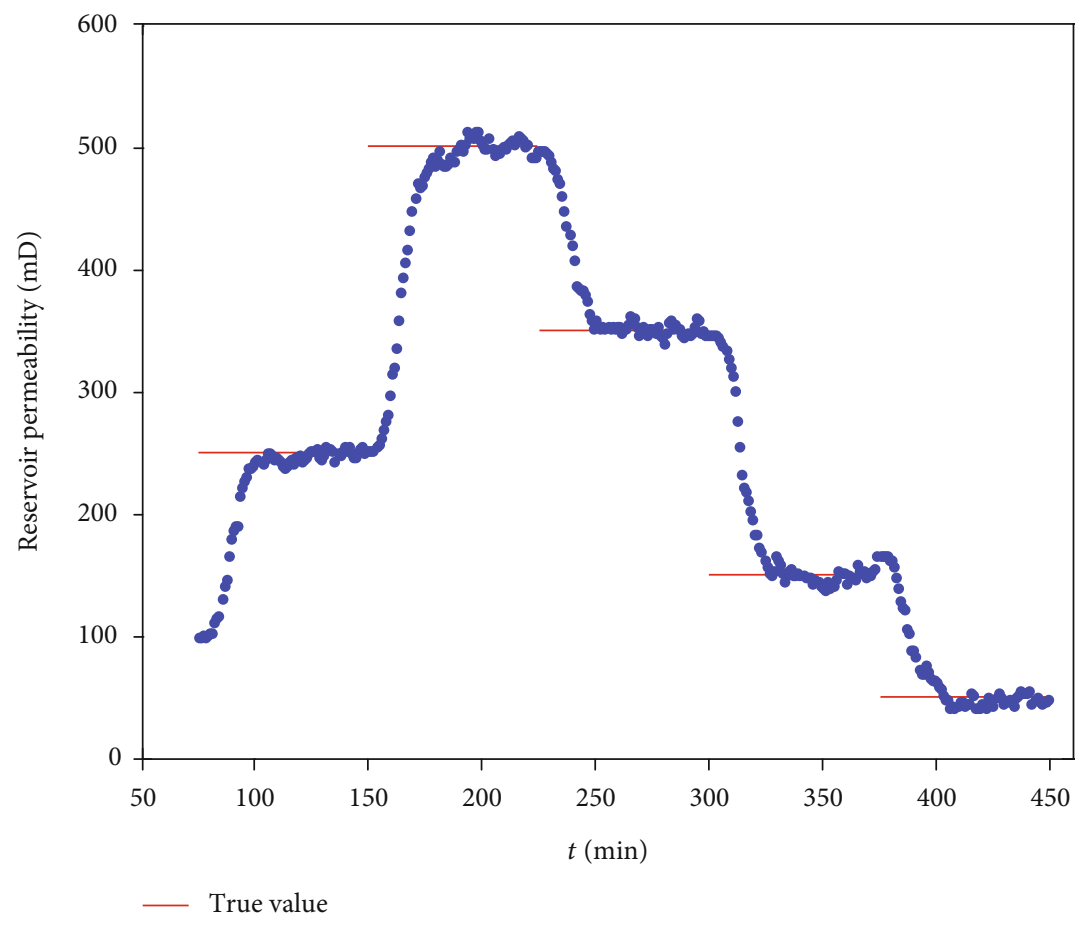

- Estimated value

Figure 5: True and estimated reservoir permeability (case 1). 


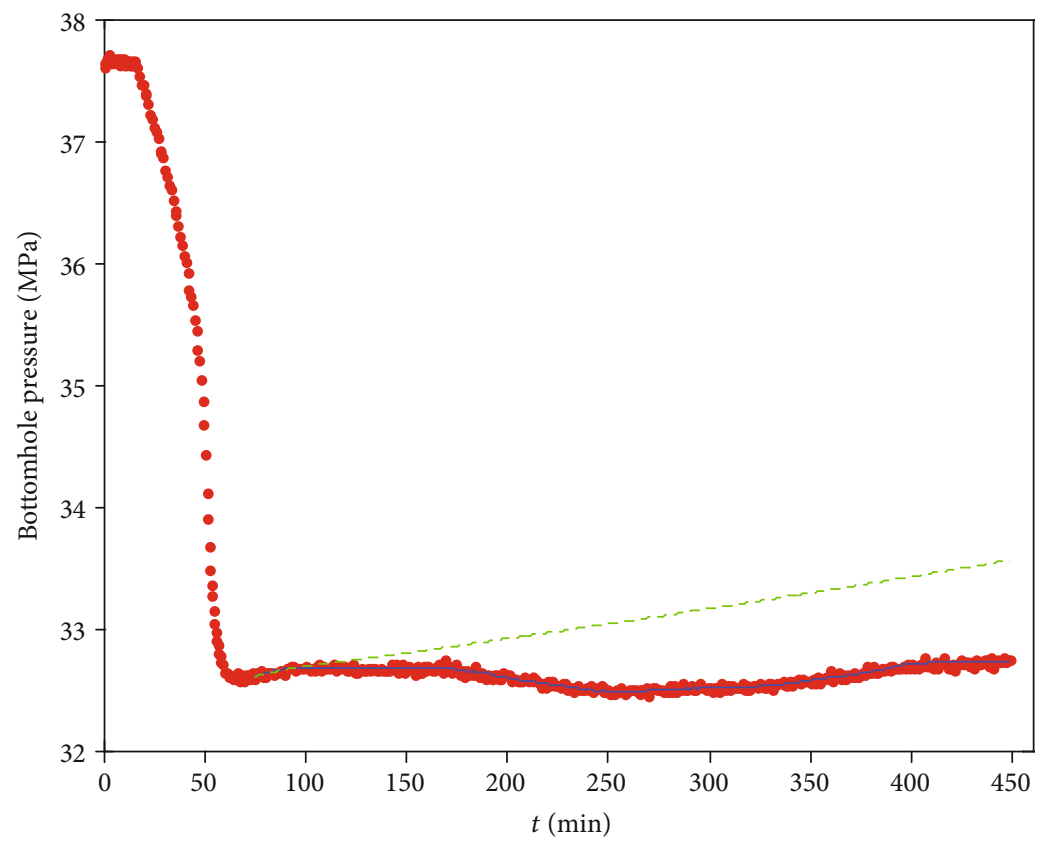

- Measurements

Estimated data

- - - Nonfiltered data

Figure 6: Bottomhole pressure variation (case 2).

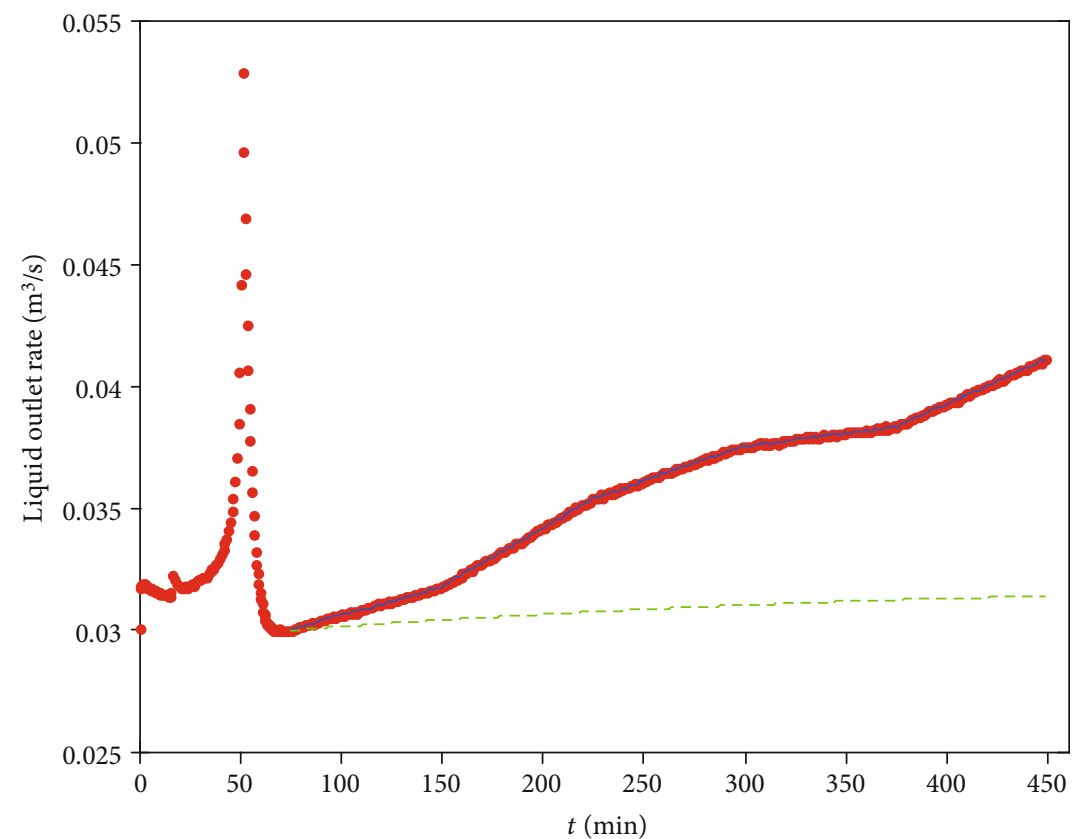

- Measurements

Estimated data

Nonfiltered data

FIgURE 7: Liquid outlet rate variation (case 2). 


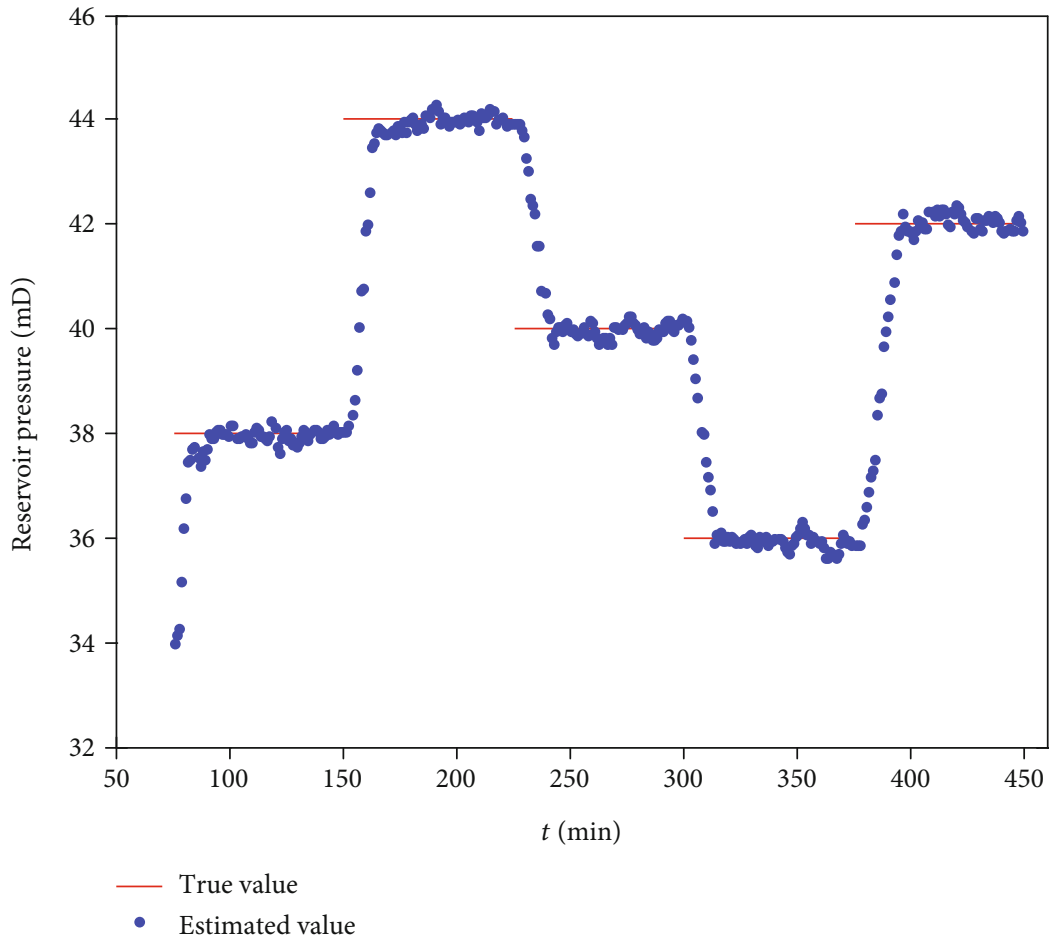

Figure 8: True and estimated reservoir pressure (case 2).

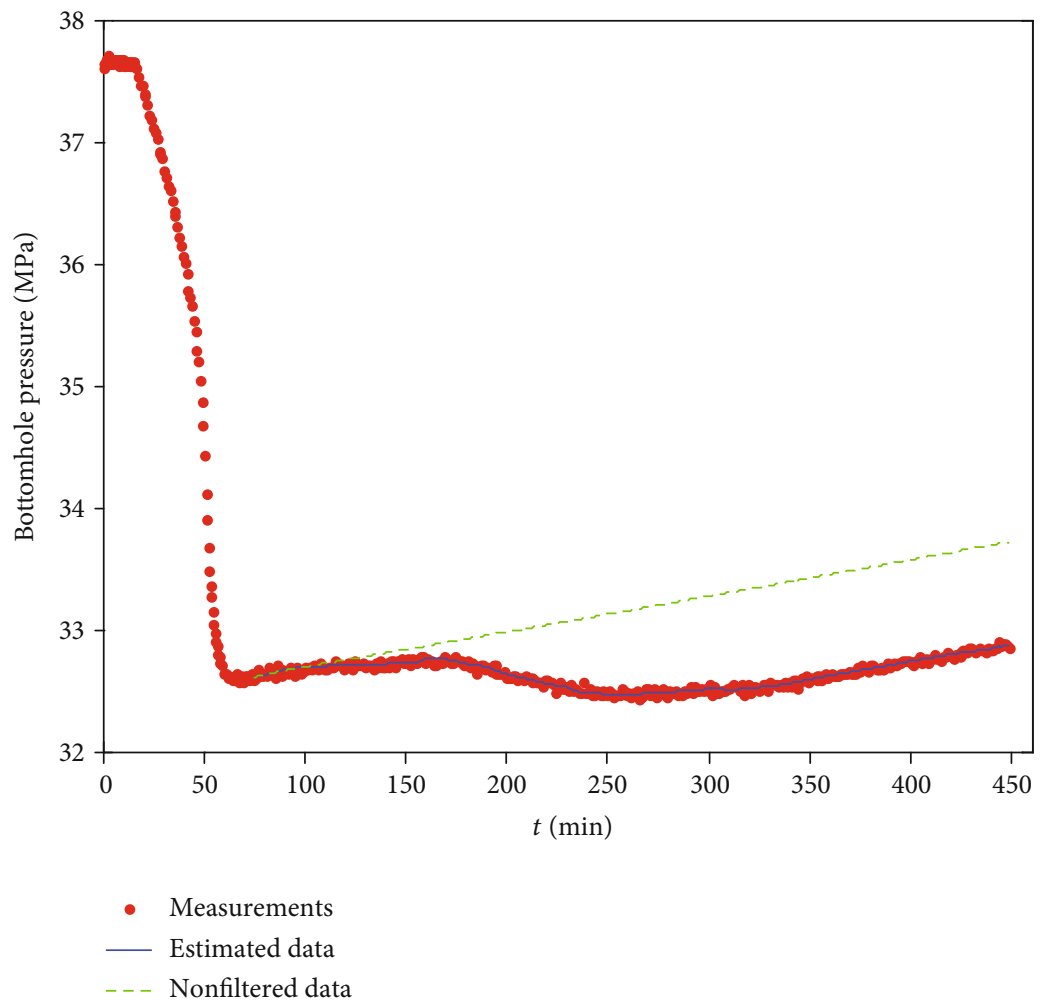

FIGURE 9: Bottomhole pressure variation (case 3).

and outlet flow rate are highly consistent with the measured values. Bottomhole pressure gradually decreases with the increase in crude oil production during $150-225 \mathrm{~min}$. In
225-300 min, the effects of the increase in crude oil production and the prolongation of the reservoir section on the bottomhole pressure offset each other, thus basically remaining 


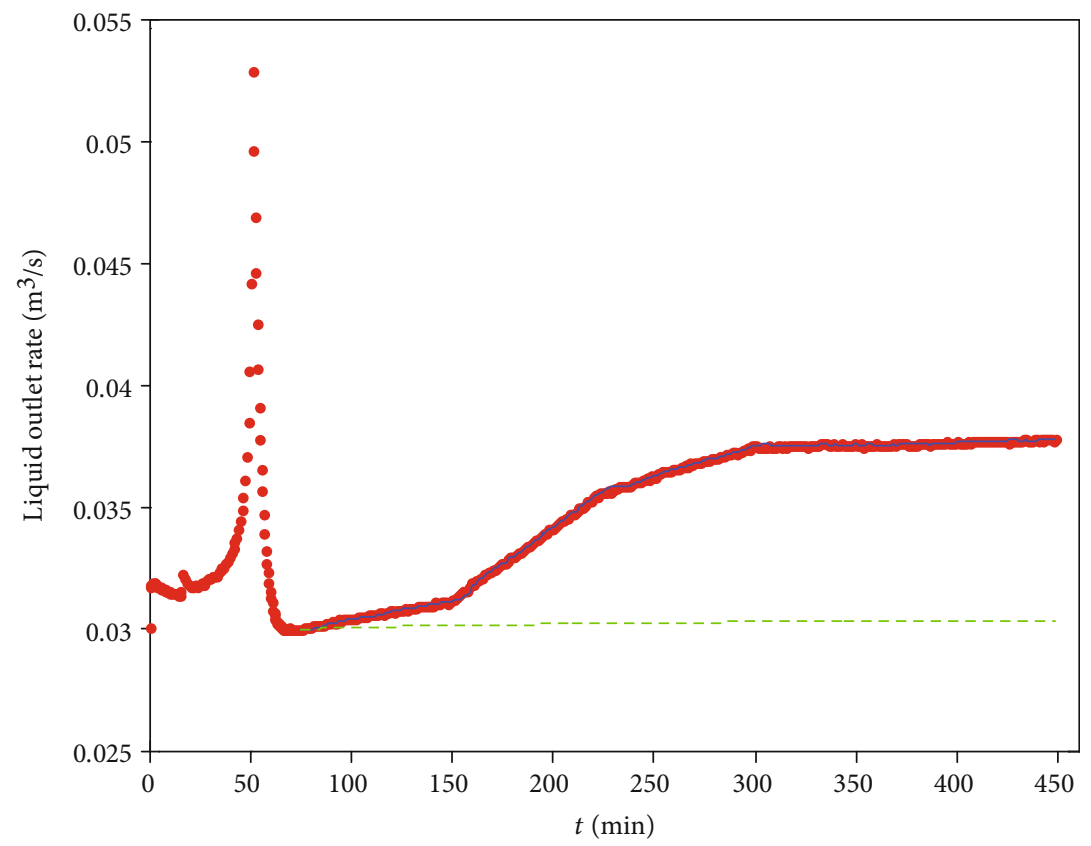

- Measurements

- Estimated data

- - Nonfiltered data

Figure 10: Liquid outlet rate variation (case 3).

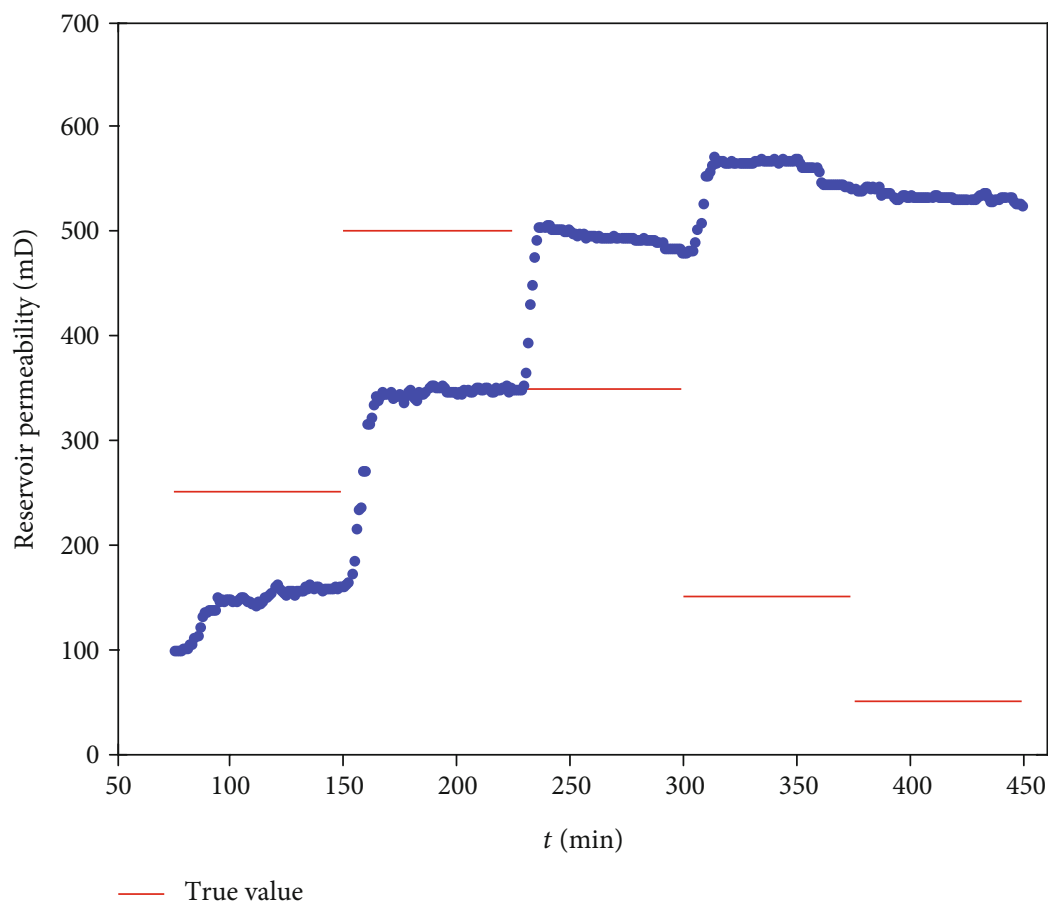

- Estimated value

FIgURE 11: True and estimated reservoir permeability (case 3).

unchanged. In 300-450 min, the prolongation of the reservoir section becomes the main controlling factor, which results in the gradual increase in bottomhole pressure. It is obvious that there are five different stages of slope change in the outlet flow rate, which matches with five different reservoir units drilled. 


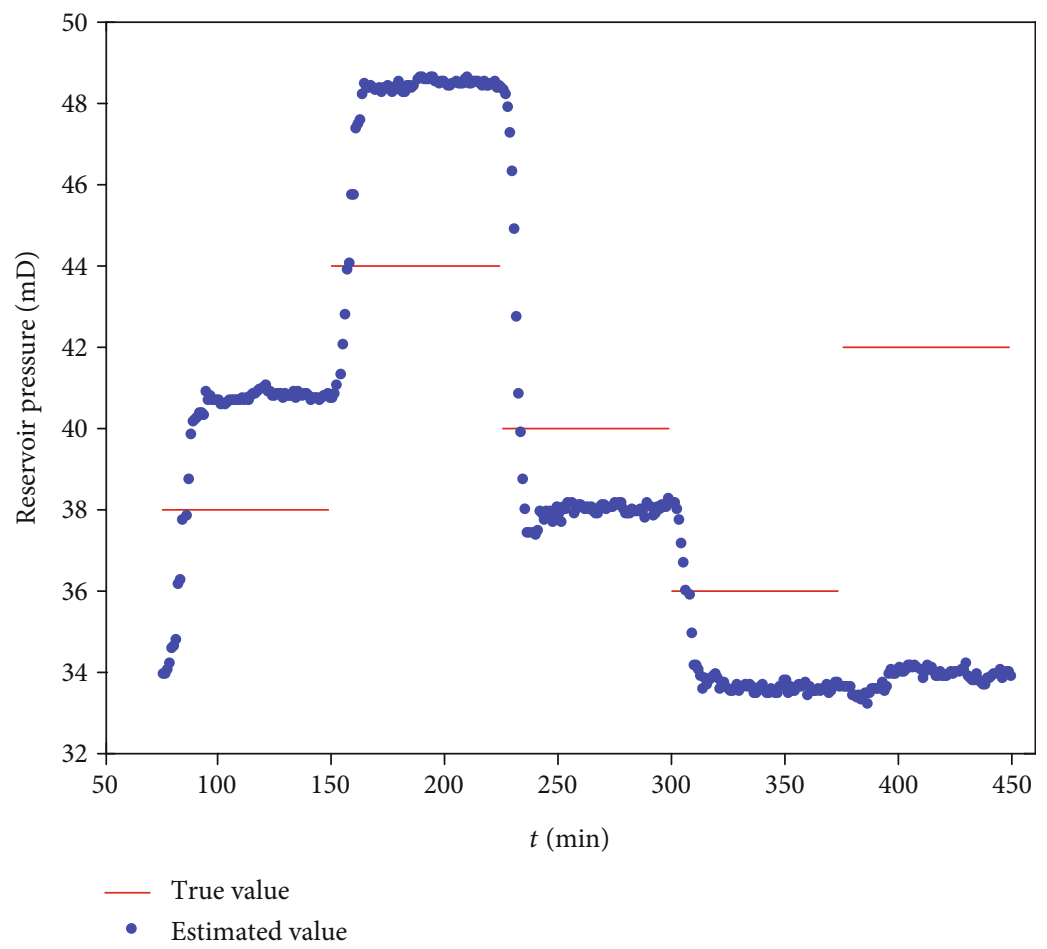

FIGURE 12: True and estimated reservoir pressure (case 3).

Figures 11 and 12 show the contrasting results of true and estimated reservoir permeability and pressure, respectively. It can be seen that the true values of reservoir permeability and pressure of each unit are $[250,500,350,150,50] \mathrm{mD}$ and $[38$, $44,40,36,42] \mathrm{MPa}$, respectively, and the initial values are set to $100 \mathrm{mD}$ and $34 \mathrm{MPa}$, respectively. The estimated values of reservoir permeability and pressure are quite different from the true values, which basically do not coincide with each other. When the permeability estimates are lower than the true values, the reservoir pressure estimates are higher and vice versa.

In summary, the single-parameter estimation of reservoir permeability or pressure in case 1 and case 2 can achieve realtime and accurate interpretation. However, the doubleparameter estimation of reservoir permeability and pressure in case 3 cannot be realized and the interpretation accuracy is low. The reason is that for the two-parameter estimation, the reservoir permeability and pressure are only related to the crude output according to the dynamic reservoir model. Two measurements in this model are too few to obtain enough effective information. However, it is also difficult to obtain effective information for the four measurements in the previous researches. It is not feasible to simply increase the number of measurement parameters, which are both related to pressure or flow rate. Therefore, by increasing measurement dimensions (e.g., dielectric constant or resistivity) and digging useful measurements in depth, synchronous estimation of two or even multiple parameters of reservoir characteristics may be realized.

Taking the single-parameter estimation of reservoir permeability in case 1 as an example, the UKF algorithm and
EKF algorithm are compared and analyzed, as shown in Figure 13. The simulation results are shown in Table 2. The average reservoir permeability while drilling through each reservoir unit is used as the estimated value. Compared with EKF, the estimated values of UKF in units 1-5 are both closer to the true value. Moreover, it takes less time for UKF estimation error to converge to $10 \%$ than it is for EKF. Only when reservoir unit 5 is used, time of convergence to $10 \%$ is higher than that for EKF, which may be related to the randomness of model noise. The numerical results show that UKF is superior to EKF in both estimation accuracy and convergence speed, which further indicates the superiority and accuracy of this model.

\section{Conclusion}

(1) A novel interpretation model while underbalanced drilling based on the UKF and three-phase variable mass flow model of oil, gas, and liquid is established. The measurement parameters are simplified to bottomhole pressure and liquid outlet flow, to continuously update the permeability and reservoir pressure along the well, helping the management of the wellbore during the UBD and follow-up completion operations

(2) Three cases including reservoir permeability and pressure single-parameter estimation and doubleparameter estimation are simulated. The results show that the interpretation accuracy of single-parameter estimation is high and the filtered values of 


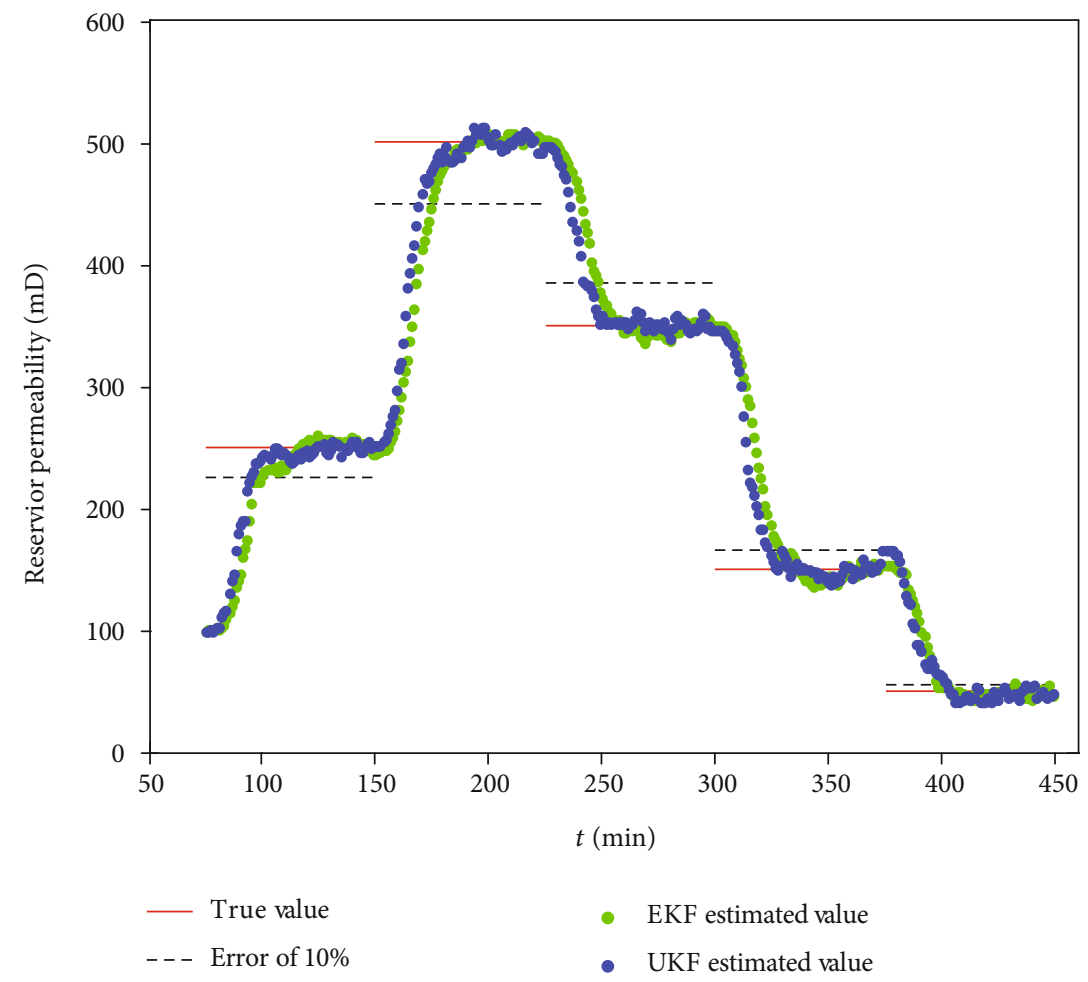

FIGURE 13: Comparison between EKF and UKF of the true and estimated value (case 1).

TABLE 2: Comparative analysis of EKF and UKF estimated results.

\begin{tabular}{|c|c|c|c|c|c|}
\hline \multirow[t]{2}{*}{ Reservoir unit } & \multicolumn{3}{|c|}{ Reservoir permeability (mD) } & \multicolumn{2}{|c|}{$\begin{array}{c}\text { Time of convergence to } \\
10 \%(\mathrm{~min})\end{array}$} \\
\hline & True value & UKF & $\mathrm{EKF}$ & UKF & EKF \\
\hline 1 & 250 & 218 & 213 & 21 & 26 \\
\hline 2 & 500 & 450 & 439 & 21 & 26 \\
\hline 3 & 350 & 379 & 386 & 18 & 25 \\
\hline 4 & 150 & 189 & 198 & 25 & 29 \\
\hline 5 & 50 & 69 & 71 & 27 & 25 \\
\hline
\end{tabular}

bottomhole pressure and outlet flow trace the measured values in real time. When a new section of the reservoir is opened, the estimated reservoir permeability or pressure can always be quickly and accurately returned to its true value. However, the double-parameter estimation cannot be realized, and the interpretation accuracy is low

(3) The comparison between the UKF and the EKF is carried out. The results show that UKF is superior to EKF in both estimation accuracy and convergence speed, which further illustrates the superiority and accuracy of the new model for interpretation while underbalanced drilling based on UKF

(4) Although the presented study is promising, for addressing the problem of joint state-andparameter estimation of a multiphase flow during drilling, further development of the methodology is needed. Future works will include how to achieve the double-parameter or even multipleparameter estimation for reservoir characteristics and the application of the methodology to actual oilfield experiments

\section{Data Availability}

The data used to support the findings of this study are available from the corresponding author upon request.

\section{Conflicts of Interest}

The authors declare that they have no conflicts of interest. 


\section{Authors' Contributions}

Miao He conceived and designed the study and performed the modelling. Yihang Zhang wrote the manuscript. Mingbiao $\mathrm{Xu}$ reviewed and edited the manuscript. Jun Li performed the data analyses. Jianjian Song helped perform the analysis with constructive discussions.

\section{Acknowledgments}

The authors would like to thank the National Natural Science Foundation of China (Grant Nos. 51904034 and 51734010) for the financial support and the National Major Science and Technology Projects of China (Grant numbers 2016ZX05060 and 2017ZX05032004-004).

\section{References}

[1] J. Daszyński, A. Rosiek, and S. Lopaciuk, "The utilization of underbalanced drilling technology may minimize tight gas reservoir formation damage: a review study," International Journal of Engineering Trends \& Technology, vol. 5, no. 1, pp. 139-143, 2013.

[2] K. A. Fattah, S. M. El-Katatney, and A. A. Dahab, "Potential implementation of underbalanced drilling technique in Egyptian oil fields," Journal of King Saud University-Engineering Sciences, vol. 23, no. 1, pp. 49-66, 2011.

[3] T. Pedersen, U. J. F. Aarsnes, and J. M. Godhavn, "Flow and pressure control of underbalanced drilling operations using NMPC," Journal of Process Control, vol. 68, pp. 73-85, 2018.

[4] A. Shadravan, M. Nabaei, and M. Amani, "Utilizing UBD technology for future development of Parsi oilfield, challenges and opportunities," in SPE Offshore Europe Oil and Gas Conference and Exhibition, Aberdeen, UK, 2009.

[5] B. Guo, H. Zhang, and Y. Feng, "Using water to control water in underbalanced drilling with nitrogen," in SPE International Symposium and Exhibition on Formation Damage Control, Lafayette, Louisiana, USA, 2014.

[6] M. Carrera, H. Hadhrami, and H. Jabri, "Successful use of underbalance drilling in a cluster of fields, North Oman at Petroleum Development Oman," in SPE/IADC Managed Pressure Drilling and Underbalanced Operations Conference and Exhibition, Abu Dhabi, UAE, 2008.

[7] C. B. Kardolus and C. P. J. W. Kruijsdijk, "Formation testing while underbalanced drilling," in SPE Annual Technical Conference and Exhibition, San Antonio, TX, USA, 1997.

[8] R. Rommetveit, O. Saevareid, A. C. V. M. Lage et al., "Dynamic underbalanced drilling effects are predicted by design model, Aberdeen, UK, 1999.

[9] A. C. V. M. Lage, K. K. Fjelde, and R. W. Time, "Underbalanced drilling dynamics: two-phase flow modeling and experiments," in IADC/SPE Asia Pacific Drilling Technology, Kuala Lumpur, Malaysia, 2000.

[10] K. K. Fjelde, R. Rommetveit, A. Merlo, and A. C. V. M. Lage, "Improvements in dynamic modeling of underbalanced drilling," in IADC/SPE Underbalanced Technology Conference and Exhibition, Houston, Texas, 2003.

[11] C. P. Perez-Tellez, J. R. Smith, and J. K. Edwards, "A new comprehensive, mechanistic model for underbalanced drilling improves wellbore pressure prediction," SPE Drilling and Completion, vol. 18, no. 3, pp. 199-208, 2013.
[12] M. Khezrian, E. Hajidavalloo, and Y. Shekari, "Modeling and simulation of under-balanced drilling operation using twofluid model of two-phase flow," Chemical Engineering Research and Design, vol. 93, pp. 30-37, 2015.

[13] E. H. Vefring, G. Nygaard, K. K. Fjelde, R. J. Lorentzen, G. Nævdal, and A. Merlo, "Reservoir characterization during underbalanced drilling: methodology, accuracy, and necessary data," in SPE Annual Technical Conference and Exhibition, San Antonio, Texas, 2002.

[14] G. Tang, Well test interpretation while underbalanced drilling, [Ph.D. thesis], Southwest Petroleum University, Chengdu, 2004.

[15] E. H. Vefring, G. Nygaard, R. J. Lorentzen, G. Nævdal, and K. K. Fjelde, "Reservoir characterization during UBD: methodology and active tests," in IADC/SPE Underbalanced Technology Conference and Exhibition, Houston, Texas, 2003.

[16] T. Nazari, V. Mostafavi, and G. Hareland, "UKF-based estimation fusion of underbalanced drilling process using pressure sensors, Singapore, 2009IEEE Instrumentation \& Measurement Technology Conference.

[17] R. Lorentzen, G. Nævdal, and A. Lage, "Tuning of parameters in a two-phase flow model using an ensemble Kalman filter," International Journal of Multiphase Flow, vol. 29, no. 8, pp. 1283-1309, 2003.

[18] A. Nikoofard, T. A. Johansen, and G. O. Kaasa, "Nonlinear moving horizon observer for estimation of states and parameters in under-balanced drilling operations," in ASME 2014 Dynamic Systems and Control Conference, San Antonio, TX, USA, 2014.

[19] A. Nikoofard, U. J. F. Aarsnes, T. A. Johansen, and G.O. Kaasa, "State and parameter estimation of a drift-flux model for underbalanced drilling operations," IEEE Transactions on Control Systems Technology, pp. 1-10, 2017.

[20] G. H. Nygaard, E. H. Vefring, K. K. Fjelde, G. Naevdal, R. J. Lorentzen, and S. Mylvaganam, "Bottomhole pressure control during drilling operations in gas-dominant wells," SPE Journal, vol. 12, no. 1, pp. 49-61, 2013.

[21] J. E. Gravdal, R. J. Lorentzen, K. K. Fjelde, and E. H. Vefring, "Tuning of computer model parameters in managedpressure drilling applications using an unscented-Kalmanfilter technique," SPE Journal, vol. 15, no. 3, pp. 856-866, 2013.

[22] C. S. Avelar, P. R. Ribeiro, and K. Sepehrnoori, "Deepwater gas kick simulation," Journal of Petroleum Science and Engineering, vol. 67, no. 1-2, pp. 13-22, 2009.

[23] K. Kinik, F. Gumus, and N. Osayande, "A case study: first field application of fully automated kick detection and control by MPD system in Western Canada," in SPE/IADC Managed Pressure Drilling \& Underbalanced Operations Conference \& Exhibition, Madrid, Spain, 2014.

[24] D. Y. Peng and D. B. Robingson, "A new two-constant equation of state," Industrial Engineering Chemistry Fundamentals, vol. 15, no. 1, pp. 59-64, 1976.

[25] E. F. Caetano, Upward two-phase flow through an annulus, [Ph.D. thesis], The University of Tulsa, 1985.

[26] A. R. Hasan and C. S. Kabir, "A study of multiphase flow behavior in vertical wells," SPE Production Engineering, vol. 3, no. 2, pp. 263-272, 1988.

[27] A. C. V. M. Lage and R. W. Time, "Mechanistic model for upward two-phase flow in annuli," in SPE Annual Technical Conference and Exhibition, Dallas, Texas, 2000. 
[28] M. He, M. Xu, J. Li, and G. Liu, "A new two-phase model to simulate sour gas kicks in MPD operations with water based mud," Journal of Petroleum Science and Engineering, vol. 159, pp. 331-343, 2017.

[29] L. P. Dake, Fundamentals of Reservoir Engineering, Elsevier, Developments in Petroleum Science, 1978.

[30] R. E. Kalman, "A new approach to linear filtering and prediction problems," Journal of Basic Engineering, vol. 82, no. 1, pp. 35-45, 1960.

[31] R. S. Bucy and K. D. Renne, "Digital synthesis of non-linear filters," Automatica, vol. 7, no. 3, pp. 287-298, 1971.

[32] S. J. Julier and J. K. Uhlmann, "New extension of the Kalman filter to nonlinear systems," in Signal Processing, Sensor Fusion, and Target Recognition VI, Orlando, FL, USA, 1997.

[33] S. J. Julier, "The scaled unscented transformation," in Proceedings of the 2002 American Control Conference (IEEE Cat. No.CH37301),, Anchorage, AK, USA, 2002. 